SUBJECT AREAS: MAGNETIC MATERIALS NANOPARTICLES

Received 12 October 2014 Accepted 4 November 2014 Published 27 November 2014

Correspondence and requests for materials should be addressed to Y.J. lyiiang@ustb.edu. $\mathrm{cn})$ or J.-P.W. (jpwang@umn.edu)

\section{Evaluation of Hyperthermia of Magnetic Nanoparticles by Dehydrating DNA}

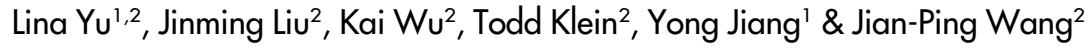

'State Key Laboratory for Advanced Metals and Materials, School of Materials Science and Engineering, University of Science and Technology Beijing, Beijing, 100083, China, ${ }^{2}$ Department of Electrical and Computer Engineering, University of Minnesota, Minneapolis, MN. 55455, USA.

A method based on the thermodynamic equilibrium reached between the hybridization and denaturation of double-stranded DNA (ds-DNA) is opened up to evaluate the hyperthermia performance of magnetic nanoparticles (MNPs). Two kinds of MNPs with different sizes and magnetic performance are chosen, and their temperature increments at the surface area under an alternating magnetic field (AMF) are calculated and compared through the concentration variation of ds-DNA modified on the surface. The temperature difference between the surface area of MNPs and bulk solution is also investigated, which can reach as high as $57.8^{\circ} \mathrm{C}$ when AMF applied for $300 \mathrm{~s}$. This method provides a direct path way of comparison hyperthermia ability of MNPs, and serves as a good reference to choose MNPs and decides the therapy parameters based on the unique drug response of individual patient.

agnetic nanoparticles (MNPs) are used for various biomedical applications and make groundbreaking improvements in diagnostics and therapeutics due to their unique magnetic performance under different kinds of magnetic fields ${ }^{1-3}$. Under an alternating magnetic field (AMF), MNPs go through Néel and Brownian relaxation and generate thermal energy which can be used to hyperthermically treat cancers due to the different thermotolerance discovered between tumor and normal cells ${ }^{4,5}$. The hyperthermia treatment could also combine with chemotherapy to build a heat-induced drug release system to enhance the therapeutic effect, and many encouraging results have been reported ${ }^{6-8}$. In this heat-induced drug release system, the chemotherapeutics are either directly bound to MNPs or encapsulated by thermosensitive materials, and the heat produced by MNPs under AMF can break the linker molecules ${ }^{9}$ or crack/melt the wrapping materials to release the drugs in vivo ${ }^{10,11}$. Because the position and heat produced by MNPs can be easily tailored by adjusting the amplitude and duration time of applied magnetic field, MNPs serve as great nanoplatforms for the on-demand drug release to reduce potential side effects, improve therapeutic outcome and realize the personalized medicine. The dose released highly dependents on breaking of the linker or cracking/melting of the wrapping materials, which, in turn, are determined by the temperature at the MNPs surface. The temperature at MNPs surface is typically considered different from the surroundings due to heat capacity and heat transfer mechanisms in the surrounding materi$\mathrm{als}^{12}$, and may rise up significantly while only a microscopic change can be observed in the bulk solution. Consequently, it is inaccurate to choose MNPs, magnetic field strengths, alternating field frequencies and exposure time based on the temperature change of the bulk solution. In order to build up high-quality clinical trials, a method which can monitor the temperature change at MNPs surface is highly demanded.

To date, it is still a challenge to determine the temperature change at the surface of nanoparticles (NPs). Some attempts have been done to investigate the nanoenviroment around the MNPs using the chemical bond breaking, bioactivity change or fluorescent optical signal variation of certain well-designed thermosensitive molecules ${ }^{13-15}$. It is noteworthy that there is a kind of naturally occurring thermosensitive biological molecule which is doublestranded DNA (ds-DNA). The ds-DNA is formed by hybridization of complementary strands and could separate into single-stranded DNA (ss-DNA) when temperature rises. Taking advantage of this fine-turned thermosensitive property, ds-DNA is designed to the MNPs based drug release system and severs as a gatekeeper to control the drug release rate ${ }^{16}$. The thermodynamic equilibrium between denaturation and hybridization of ds-DNA can be quickly obtained, based on which a thermodynamic equation can be built to express the relationship between temperature and the concentration of ds-DNA. Therefore, ds-DNA could be used as a thermo probe to map the surrounding temperature at the surface of MNPs during the hyperthermia process, and the temperature detection range can be varied easily through the design of $\mathrm{DNA}^{17}$.

The heating ability of MNPs is defined as the specific loss powers (SLPs), and it is determined by many parameters such as the particle material, size, shape as well as strength and frequency of AMF etc ${ }^{18}$. Therefore, 
it is not appropriate to compare SLPs of different MNPs just simply relying on one parameter. Dehydrating ds-DNA provides a simple and direct method to compare the hyperthermia ability of different MNPs under different AMF and duration time. It is also a good reference to choose MNPs and decide the therapy parameters based on the unique drug response of individual patient by comparing the hyperthermia effect on different kinds of MNPs.

\section{Results}

In this paper, we use two kinds of MNPs with different magnetic moments and sizes to explore their temperature variation during the hyperthermia process through the concentration change of ds-DNA on the surface, as illustrated in Figure 1. Both MNPs have carboxylic acid group on the surface which can be activated by EDC/sulfo-NHS. Then the ds-DNA is attached on the MNPs surface in which one of the two strands with amine group modified is anchored to the surface of MNPs through the reaction with carboxylic acid group, and the other strand is hybridized with the covalently bond strand forming ds-DNA. After washing the free DNA without conjunction on MNPs, the MNPs heat up by applying AMF, and the nonchemical bonded strands dislocate into the surrounding medium. Then a centrifuge process is quickly carried out to separate the released ssDNA from MNPs, and measure the concentration of ds-DNA left on the MNPs to determine the ds-DNA fraction. The AMF is applied for different time, and the amount changes of ds-DNA on both MNPs are determined. Based on the ds-DNA fraction, the temperature around the MNPs is calculated, and the hyperthermia properties of each MNP can be evaluated.

The TEM images of two kinds of $\mathrm{Fe}_{3} \mathrm{O}_{4}$ MNPs are given in Figure 2. Figure 2a depicts the morphology of $\mathrm{Fe}_{3} \mathrm{O}_{4}$ MNPs with low magnetic moment (expressed as $\mathrm{LM} \mathrm{Fe}_{3} \mathrm{O}_{4} \mathrm{MNPs}$ ). The LM $\mathrm{Fe}_{3} \mathrm{O}_{4} \mathrm{MNPs}$ are spherical with a uniform diameter of $8 \mathrm{~nm}$. The diffraction pattern shows a diffusion halo which means poor crystallinity. The morphology of $\mathrm{Fe}_{3} \mathrm{O}_{4}$ MNPs with high magnetic moment (expressed as $\mathrm{HM} \mathrm{Fe} \mathrm{F}_{3} \mathrm{O}_{4}$ MNPs) is similar with LM $\mathrm{Fe}_{3} \mathrm{O}_{4}$ MNPs, as shown in Figure 2b. The $\mathrm{HM} \mathrm{Fe} \mathrm{O}_{4} \mathrm{MNPs}$ are spherical with diameters of $18 \mathrm{~nm}$. Different from $\mathrm{LM} \mathrm{Fe}_{3} \mathrm{O}_{4}$ MNPs, a complex asymmetric diffraction pattern is observed in the $\mathrm{HM} \mathrm{Fe} \mathrm{O}_{4} \mathrm{MNPs}_{4}$ diffraction image, which means better crystallinity for $\mathrm{HM} \mathrm{Fe}_{3} \mathrm{O}_{4} \mathrm{MNPs}$. Figure $2 \mathrm{c}$ and d give the magnetic hysteresis loops of $\mathrm{LM}$ and $\mathrm{HM} \mathrm{Fe}_{3} \mathrm{O}_{4} \mathrm{MNPs}$, respectively. The approximate zero coercivity and reversible hysteresis behavior are observed, indicating the superparamagnetic nature for both $\mathrm{LM}$ and $\mathrm{HM} \mathrm{Fe} \mathrm{F}_{3}$ MNPs, because their sizes are below the superparamagnetic critical dimension. The saturation magnetization $\left(\mathrm{M}_{\mathrm{S}}\right)$ of $\mathrm{HM} \mathrm{Fe}_{3} \mathrm{O}_{4} \mathrm{MNPs}$ is $104 \mathrm{emu} / \mathrm{g}$ Fe much higher than that of $\mathrm{LM} \mathrm{Fe}_{3} \mathrm{O}_{4}$ MNPs which is about $41 \mathrm{emu} / \mathrm{g}$ Fe. From the TEM images, this difference of magnetic properties should be mainly attributed to the crystallinity of MNPs and size effect.

The attachment of ds-DNA is through the carboxyl-to-amine crosslinking between ds-DNA and MNPs using the EDC and sulfo-NHS. The amount of ds-DNA attached on per HM MNP is quantitatively analyzed and optimized through changing the addition of ds-DNA. The number of ds-DNA attached on per MNP is 949 when the $50 \mathrm{nM}$ ds-DNA is used. The number of ds-DNA on per MNP increases to 971 when the concentration of ds-DNA is reduced to $5 \mathrm{nM}$. When the concentration of ds-DNA is further reduced to $0.5 \mathrm{nM}$, there are only $682 \mathrm{ds}$-DNA can be attached on per MNP. So the $5 \mathrm{nM}$ of addition ds-DNA gives the maximum attaching amount, and this experiment condition is kept in the following experiments. The calculation details are shown in supporting information Section I.

To detect the temperature in the surface area of MNPs and figure out the temperature difference between the surrounding buffer and the surface area of both MNPs during the hyperthermia process, the temperature in bulk solution and surface area is recorded individually. For the bulk solution, the temperature variation of different concentrated $\mathrm{LM}$ and $\mathrm{HM} \mathrm{Fe} \mathrm{O}_{4}$ MNPs with respect to AMF applied time are shown in Figure 3. The liquid temperatures of all $\mathrm{LM} \mathrm{Fe}_{3} \mathrm{O}_{4}$ solutions are almost saturated when the AMF applies for $200 \mathrm{~s}$, which agrees with reported results of R. Kappiyoor et $a l^{19}$. When $\mathrm{AMF}$ is applied for $180 \mathrm{~s}$, there are $0.14,0.31$ and $0.66^{\circ} \mathrm{C}$ temperature increments observed for the 1,10 and $100 \mu \mathrm{g} / \mathrm{mL}$ LM MNPs samples, respectively. For HM MNPs, a linear temperature increase is observed within $250 \mathrm{~s}$ of AMF applied, and about $0.71,1.22$ and $1.46^{\circ} \mathrm{C}$ temperature increments are observed for 1,10 and $100 \mu \mathrm{g} /$ $\mathrm{mL}$ samples after applied AMF for $180 \mathrm{~s}$, respectively. For the HM MNPs, the steady state temperature can be observed to need a longer time, not shown here, due to larger saturation magnetization than the LM MNPs according to the Ref. 19.

For MNPs, the barriers for magnetization reversal are comparable to the thermal energy when the volume of particle is close to the critical volume. The magnetic relaxation of MNPs suspended in a carrier fluid occurs via Néel and Brownian mechanisms. The Néel relaxation is due to rapid changes in the direction of magnetic moments, hindered by magnetic anisotropy energy that tends to keep the magnetic domain of MNPs in a specific direction according to their crystal lattice structure. The Brownian relaxation is due to the
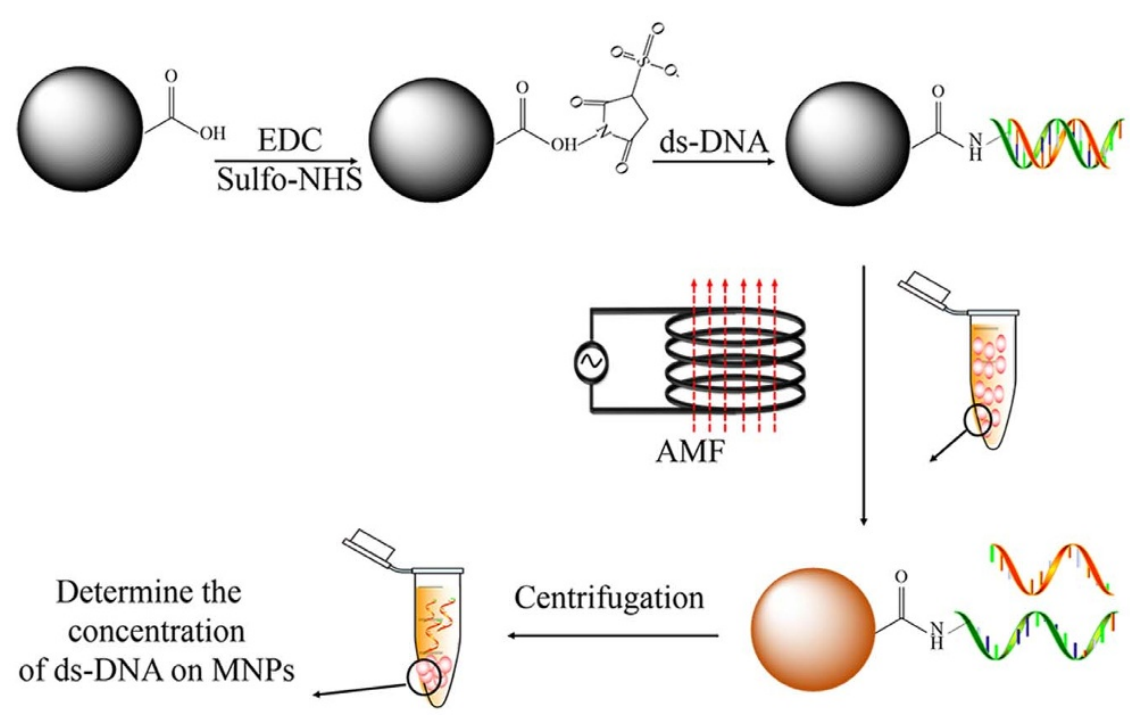

Figure $1 \mid$ Schematic picture of probing the hyperthermia effect of MNPs. 

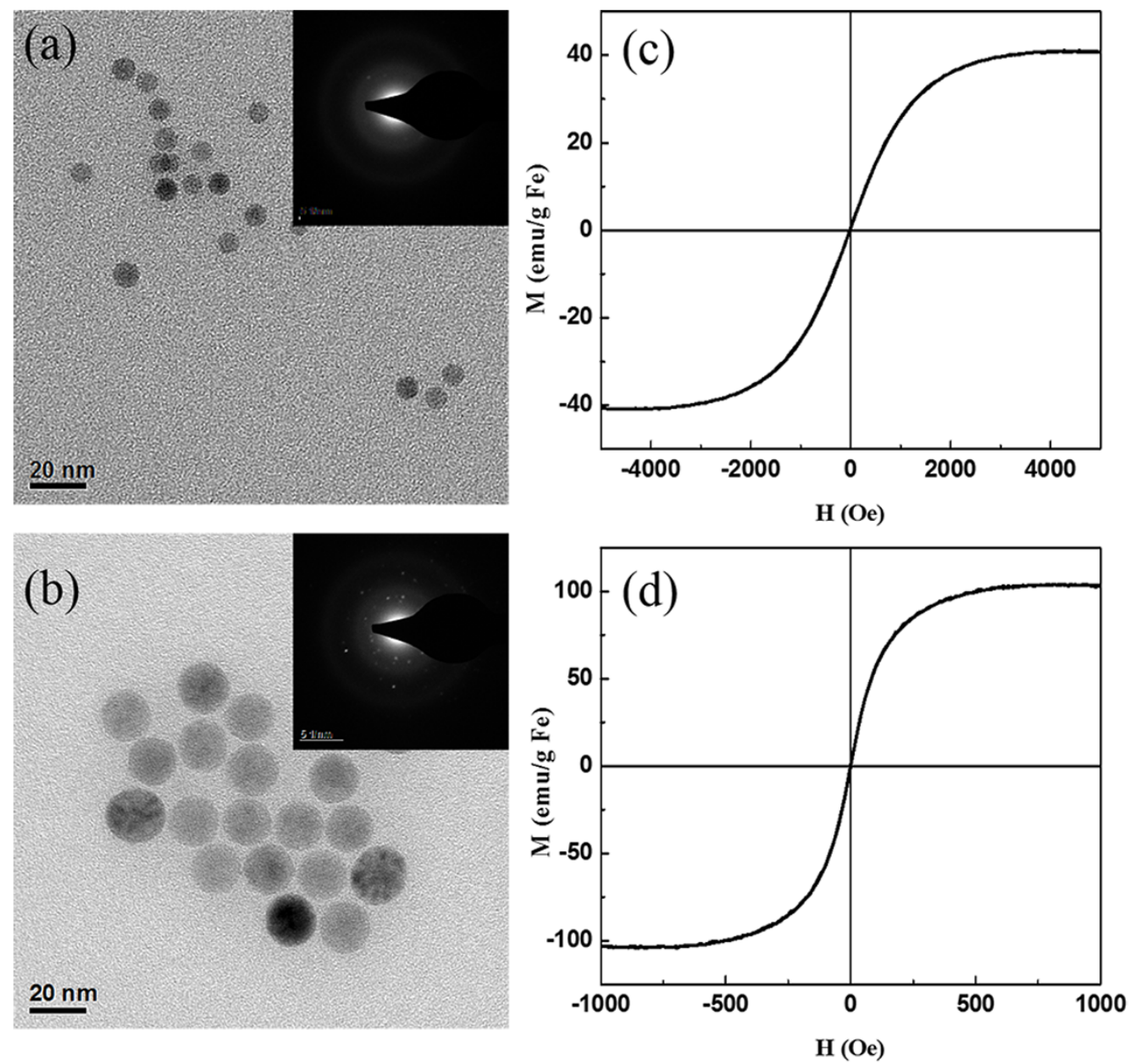

Figure $2 \mid$ TEM image of MNPs and its corresponding diffraction pattern (inset) (a) $\mathrm{LM} \mathrm{Fe}_{3} \mathrm{O}_{4} \mathrm{MNPs}$ (b) $\mathrm{HM} \mathrm{Fe}_{3} \mathrm{O}_{4} \mathrm{MNPs}$ Magnetic hysteresis loops of (c) $\mathrm{LM} \mathrm{Fe}_{3} \mathrm{O}_{4}$ MNPs (d) $\mathrm{HM} \mathrm{Fe}_{3} \mathrm{O}_{4}$ MNPs measured at room temperature.

physical rotation of particles within the dispersed medium, hindered by the viscosity of the suspended medium, which tends to counter the rotation of particles ${ }^{20,21}$. Therefore HM MNPs with higher saturation magnetization and bigger particle size can achieve better heating results when concentrations of HM and LM MNPs are same ${ }^{20}$. For the temperature increments of the bulk solution, the maximum temperature difference between LM and HM MNPs is only $0.91^{\circ} \mathrm{C}$ obtained for $10 \mu \mathrm{g} / \mathrm{mL}$ samples. The temperature increment is also very small when the concentration rises by an order of magnitude, which maybe because of the difference to variation in the rates of convective heat transfer or the orientation or agglomeration of the nanoparticles ${ }^{22}$.

The local temperature of $\mathrm{Fe}_{3} \mathrm{O}_{4}$ MNPs surface is monitored by released rate of the ds-DNA bonded on the surface (see Figure 1), and the ds-DNA fraction variation with respect of the field applied time for the concentration of $10 \mu \mathrm{g} / \mathrm{mL}$ MNPs is shown in Figure 4a. The $10 \mu \mathrm{g} / \mathrm{mL}$ of MNPs is chosen because it is a concentration with measurable ds-DNA change and relativity low dosage. When the AMF is applied for $60 \mathrm{~s}$, the ds-DNA fractions of LM and HM MNPs are $97 \%$ and $92 \%$, respectively. When the duration time is extended to $180 \mathrm{~s}$, about $86 \%$ and $68 \%$ of ds-DNA for LM and HM MNPs can still stay hybridized, respectively. If further increasing the AMF applied time to $300 \mathrm{~s}$, the ds-DNA fraction of LM and HM MNPs are reduced to $82 \%$ and $54 \%$, respectively.

Based on the thermodynamic equilibrium built between ds-DNA and ss-DNA at certain temperature, the local temperature at MNPs surface can be calculated by the Van't Hoff equation. And the rela- tion of the temperature around MNPs to the ds-DNA fraction $(f)$ can be expressed in Equation $1^{17,23}$.

$$
f=\frac{1+C_{T} K_{e q}-\sqrt{1+2 C_{T} K_{e q}}}{C_{T} K_{e q}}, \text { in here } K_{e q}=e^{\left[\frac{\Delta S}{R}-\frac{\Delta H}{R T}\right]},
$$

Where $\Delta H$ is the enthalpy change, $\Delta S$ is the entropy change, $C_{\mathrm{T}}$ is concentration of total DNA strand, and $R$ is the gas constant. The calculation results of the fraction of ds-DNA with respect to temperature are shown in Figure $4 \mathrm{~b}$, and the calculation details are given in supporting information Section II. The fraction of ds-DNA sharply decreases when the temperature is beyond about $85^{\circ} \mathrm{C}$, which means that the ds-DNA begins to drastically melt. And ds-DNA dislocates completely into ss-DNA when the temperature reaches $105^{\circ} \mathrm{C}$ for both $\mathrm{LM}$ and $\mathrm{HM} \mathrm{Fe}_{3} \mathrm{O}_{4} \mathrm{MNPs}$. The melting curves calculated for dsDNA attached on LM and HM MNPs are different because of the DNA concentration $\left(C_{\mathrm{T}}\right)$ difference in the solution for HM and LM MNPs caused by their different sizes. Compared with LM MNPs, the $\mathrm{HM} \mathrm{Fe} \mathrm{O}_{4}$ MNPs need higher local temperature to release same fraction of ds-DNA.

Combined Figure $4 \mathrm{a}$ with Figure $4 \mathrm{~b}$, the local temperature of $\mathrm{Fe}_{3} \mathrm{O}_{4}$ MNPs surface can be obtained for each time point under an individual AMF applied time, where we select three time point to test the release rate of ds-DNA $(60,180$ and $300 \mathrm{~s})$. The effective local heating can be expressed as the temperature difference $(\Delta T)$ between the local temperature $T$ (time) and the initial temperature $T(0 \mathrm{~s}): \Delta T$ $=T$ (time) $-T(0 \mathrm{~s})$, as shown in Figure $4 \mathrm{c}$. The temperature for both 
(a)

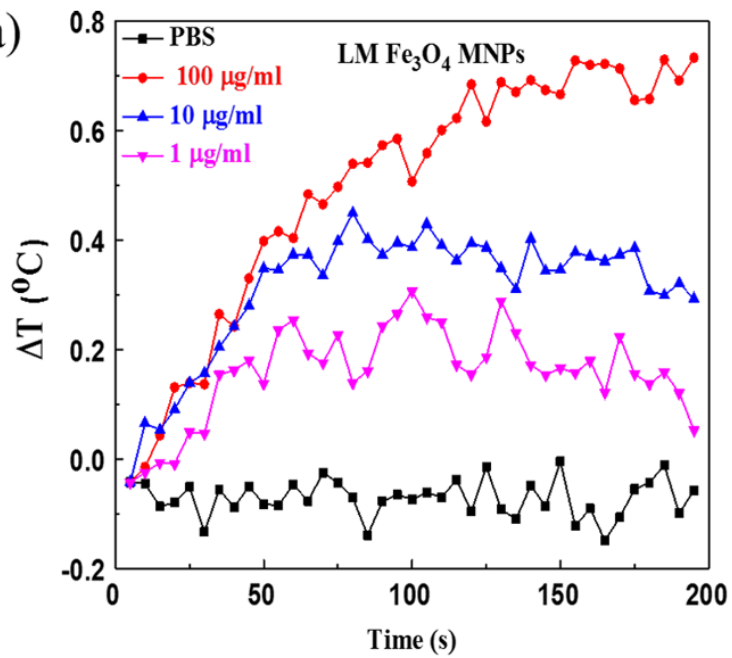

(b)

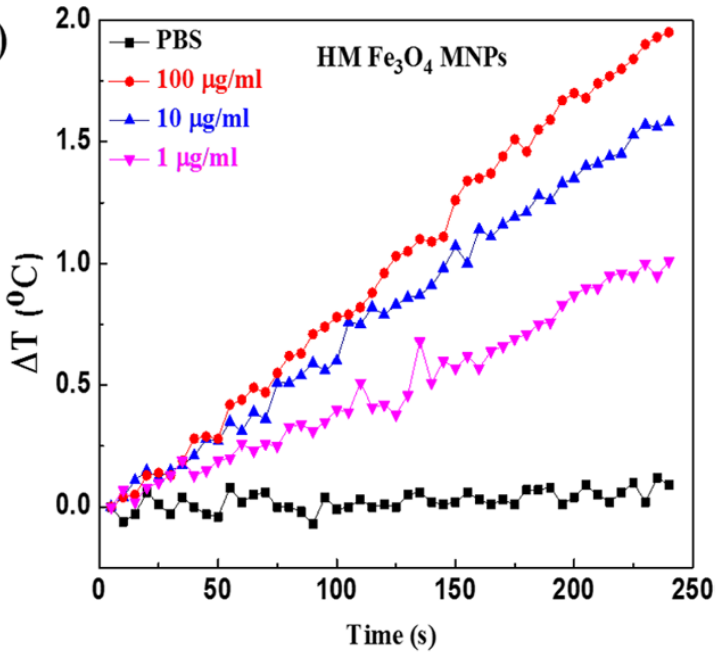

Figure 3 The curves of temperature rises with respect to AMF applied time at different concentrations of (a) $\mathrm{LM}$ and (b) $\mathrm{HM} \mathrm{Fe}_{3} \mathrm{O}_{4}$ MNPs.

LM and HM MNPs keeps increasing as the field applied time goes up from 60 to $300 \mathrm{~s}, \Delta T$ of $\mathrm{HM} \mathrm{Fe}_{3} \mathrm{O}_{4}$ MNPs is larger than that of LM $\mathrm{Fe}_{3} \mathrm{O}_{4} \mathrm{MNPs}$ for same field applied time. The temperature rises by $50.5,54.1,54.6^{\circ} \mathrm{C}$ for LM MNPs when the field applied for 60,180 and $300 \mathrm{~s}$, respectively. And for HM MNPs, the $\Delta T$ is 54.6, 58.0, $59.1^{\circ} \mathrm{C}$ for duration time of 60,180 and $300 \mathrm{~s}$, respectively. The maximum local temperature difference between HM and LM $\mathrm{Fe}_{3} \mathrm{O}_{4} \mathrm{MNPs}$ is $4.5^{\circ} \mathrm{C}$. Compared with the change of bulk solution, the temperature difference between surface and bulk solution at concentration of $10 \mu \mathrm{g} / \mathrm{mL}$ can reach as high as $53.8^{\circ} \mathrm{C}$ for $\mathrm{LM}$ MNPs and $57.8^{\circ} \mathrm{C}$ for $\mathrm{HM}$ ones when the field applied for $300 \mathrm{~s}$.

\section{Conclusion}

In conclusion, a method based on the temperature-dependent thermodynamics of the hybridization and denaturation of ds-DNA was given to evaluate the hyperthermia performance of different MNPs in this work. Based on the release ratio of ds-DNA attached on the MNPs, the local temperature at two kinds of $\mathrm{Fe}_{3} \mathrm{O}_{4}$ MNPs surface during the hyperthermia process was calculated. When AMF was applied for $300 \mathrm{~s}$, the temperature around surface for LM and HM MNPs was found to increase by $54.6^{\circ} \mathrm{C}$ and $59.1^{\circ} \mathrm{C}$, respectively. In addition, the big temperature difference was observed between the surface and bulk solution, which could reach as high as $53.8^{\circ} \mathrm{C}$ for LM MNPs and $57.8^{\circ} \mathrm{C}$ for HM ones at concentration of $10 \mu \mathrm{g} / \mathrm{mL}$ for the field applied for $300 \mathrm{~s}$. This ds-DNA based temperature detection method provides a simple and convenient way to quantitatively
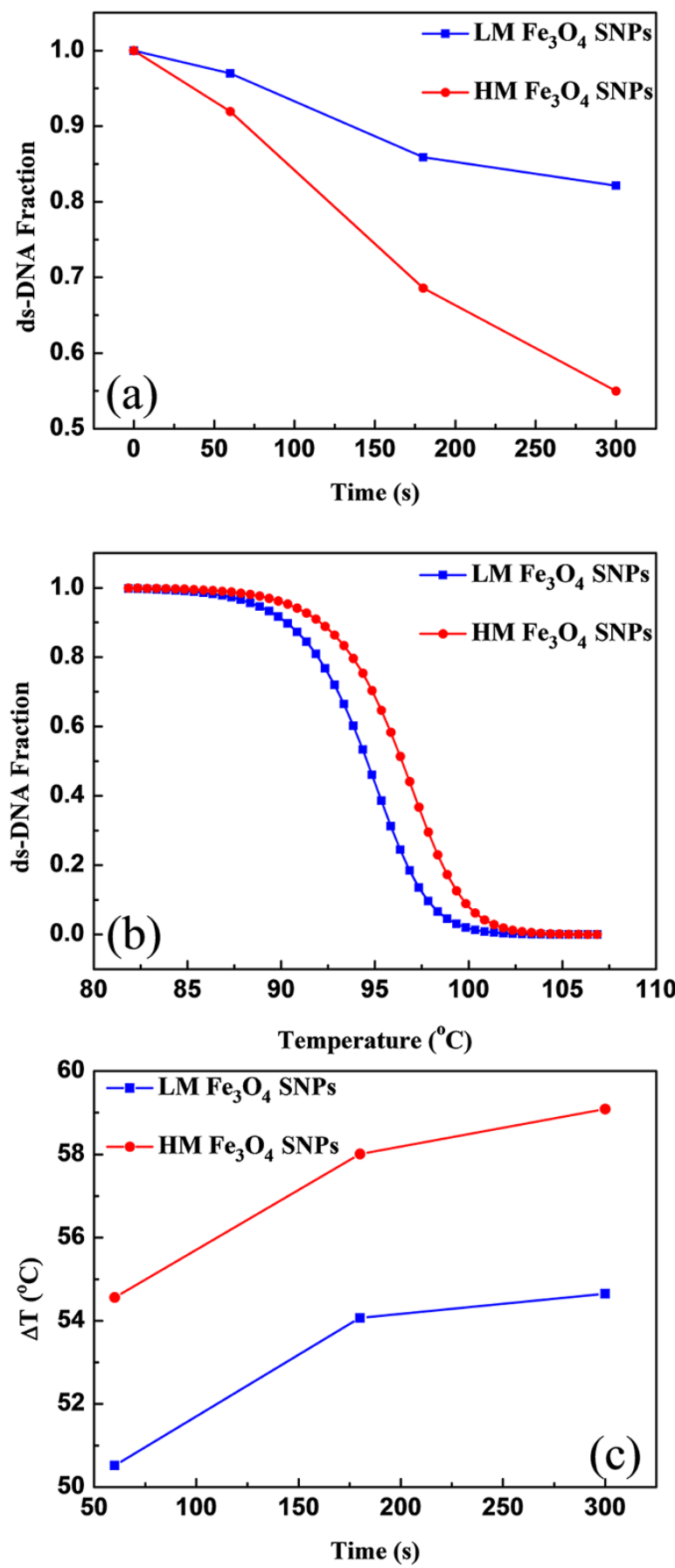

Figure $4 \mid$ (a) The ds-DNA fraction as a function of the field applied time. (b) The calculated results of quantitative correlation between released rate ds-DNA and the local temperature at MNPs Surface. (c) $\Delta \mathrm{T}$ as a function of field applied time for $\mathrm{LM}$ and $\mathrm{HM} \mathrm{Fe}_{3} \mathrm{O}_{4}$ MNPs.

monitor the temperature evolution around magnetic nanoparticles, and will open up a path for optimizing local temperature controls for different biomedical applications.

\section{Methods}

Materials. Both kinds of $\mathrm{Fe}_{3} \mathrm{O}_{4}$ MNPs with carboxyl acid on the surface were purchased from Ocean Nanotech, LLC. The one with poor magnetic performance was not well crystallized. 1-ethyl-3-[3-dimethylaminopropyl]carbodiimide hydrochloride (EDC) and N-hydroxysulfosuccinimide (sulfo-NHS) were purchased from Thermo Fisher Scientific Inc. The capture DNA oligomers with amino modification in $5^{\prime}$ end, the dehydrated DNA oligomers with biotin modification in $5^{\prime}$ end and the duplex buffer were purchased from Integrated DNA Technologies, Inc. 
The sequence of ss-DNA modified on MNPs:

1. 5' -AmMC6/ACC TTC CTC CGC AAT ACT CCC CCA GGT-3'

The sequence of ss-DNA dehydrated

2. 5' -Biosg/ACC TGG GGG AGT ATT GCG GAG GAA GGT-3

DNA Hybridization. Annealing is fairly straightforward method to hydrate complementary ss-DNA to form ds-DNA. Both of ss-DNA were dissolved in the duplex buffer to form $1 \mu \mathrm{M}$ solution. Then same volume commentary ss-DNA solutions were mixed together, put into $94^{\circ} \mathrm{C}$ oven for $5 \mathrm{~min}$ and gradually cooled down to the room temperature. The resulting product was ds-DNA, and stored at $4{ }^{\circ} \mathrm{C}$ for future usage.

Immobilized of ds-DNA oligomers on $\mathrm{Fe}_{3} \mathrm{O}_{4}$ MNPs. Briefly, both $50 \mathrm{mg} / \mathrm{mL}$ EDC and $50 \mathrm{mg} / \mathrm{mL}$ sulfo-NHS solution were freshly prepared for using. $100 \mu \mathrm{L}$ EDC solution and $100 \mu \mathrm{L}$ sulfo-NHS solution were added into $500 \mu \mathrm{L}$ MNPs $(1 \mathrm{mg} / \mathrm{mL}$ $\mathrm{Fe}$ ), and stirred for $30 \mathrm{~min}$ in dark. Then the solution was then centrifuged for $5 \mathrm{~min}$ at 14,000 rpm, and removed supernatant from the tube. The MNPs on the bottom were suspended in $0.1 \mathrm{M}$ sodium phosphate buffer $(\mathrm{pH}=6)$. This

precipitation - redispersion wash process was carried out for three times, and NPs were finally suspended in $0.1 \mathrm{M}$ sodium phosphate buffer $(\mathrm{pH}=6)$ to form $\sim 500 \mu \mathrm{g} /$ $\mathrm{mL}$ Fe solution. Then $500 \mu \mathrm{L}$ ds-DNA solution with different concentration were added into $500 \mu \mathrm{L}$ activated NPs solution, and rotated overnight in dark. The finally product was washed three times and finally in PBST buffer (PBS with $0.05 \%$ Tween 20)

Hyperthermia process. $\mathrm{Fe}_{3} \mathrm{O}_{4}$ MNPs with ds-DNA were contained in a $0.65 \mathrm{~mL}$ tube, and immersed in $37^{\circ} \mathrm{C}$ camber. An $\operatorname{AMF}\left(f=337 \mathrm{kHz}, \mathrm{H}_{0}=22 \mathrm{kA} \mathrm{m}^{-1}\right)$ was applied to heat up the system. The tube was put into ice immediately to prevent the ssDNA rehydrating again. Before measure the concentration of ds-DNA, a centrifugation process was carry out to remove released standard. The MNPs were redispersed in PBS buffer to measure the concentration of ds-DNA attached.

Instruments and Measurements. The morphology and crystallinity of $\mathrm{Fe}_{3} \mathrm{O}_{4} \mathrm{MNPs}$ used were characterized by a transmission electron microscope (TEM) (FEI, FEG $300 \mathrm{keV})$. The magnetic loops of all NPs were taken by a vibrating sample magnetometer (VSM) (Princeton Measurements). The AMF was produced by an induction coil system which has adjustable field strength and frequencies. The temperature change of MNPs solution during the heating process was monitored by a fluoroptic thermometry system (Luxtron 3100, Lumasense Technologies). After heating, the NPs solution were centrifuged, and concentration of ds-DNA on MNPs was determined by a microplate spectrophotometer (Epoch, BioTek).

1. Colombo, M. et al. Biological applications of magnetic nanoparticles. Chem. Soc. Rev. 41, 4306-4334 (2012).

2. Hao, R. et al. Synthesis, functionalization, and biomedical applications of multifunctional magnetic nanoparticles. Adv. Mater. 22, 2729-2742 (2010).

3. $\mathrm{Yu}$, J. et al. Multifunctional $\mathrm{Fe}_{5} \mathrm{C}_{2}$ nanoparticles: a targeted theranostic platform for magnetic resonance imaging and photoacoustic tomography-guided photothermal therapy. Adv. Mater. 26, 4114-4120 (2014).

4. Jordan, A. et al. Endocytosis of dextran and silan-coated magnetite nanoparticles and the effect of intracellular hyperthermia on human mammary carcinoma cells in vitro. J. Magn. Magn. Mater. 194, 185-196 (1999).

5. Moroz, P., Jones, S. K. \& Gray, B. N. Magnetically mediated hyperthermia: current status and future directions. Int. J. Hyperthermia 18, 267-284 (2002).

6. $\mathrm{Hu}, \mathrm{S}$. H. et al. Core-shell nanocapsules stabilized by single-component polymer and nanoparticles for magneto-chemotherapy/hyperthermia with multiple drugs. Adv. Mater. 24, 3627-3632 (2012).

7. López-Noriega, A. et al. Hyperthermia-induced drug delivery from thermosensitive liposomes encapsulated in an injectable hydrogel for local chemotherapy. Adv. Healthcare Mater. 3, 854-859 (2014).

8. Maier-Hauff, K. et al. Efficacy and safety of intratumoral thermotherapy using magnetic iron-oxide nanoparticles combined with external beam radiotherapy on patients with recurrent glioblastoma multiforme. J. Neurooncol. 103, 317-324 (2011)

9. N'Guyen, T. T. T. et al. Functional iron oxide magnetic nanoparticles with hyperthermia-induced drug release ability by using a combination of orthogonal click reactions. Angew. Chem. Int. Ed. 52, 14152-14156 (2013).
10. Chen, W. et al. Self-reporting liposomes for intracellular drug release. Small 10, 1261-1265 (2014).

11. Kumar, C. S. S. R. \& Mohammad, F. Magnetic nanomaterials for hyperthermiabased therapy and controlled drug delivery. Adv. Drug Delivery Rev. 63, 789-808 (2011).

12. Keblinski, P. et al. Limits of localized heating by electromagnetically excited nanoparticles. J. Appl. Phys. 100, 054305 (2006).

13. Riedinger, A. et al. Subnanometer local temperature probing and remotely controlled drug release based on Azo-functionalized iron oxide nanoparticles. Nano Lett. 13, 2399-2406 (2013).

14. Huang, H. et al. Remote control of ion channels and neurons through magneticfield heating of nanoparticles. Nat. Nanotechnol. 5, 602-606 (2010).

15. Dong, J. \& Zink, J. I. Taking the temperature of the interiors of magnetically heated nanoparticles. ACS Nano 8, 5199-5207(2014).

16. Zhou, S., Du, X., Cui, F. \& Zhang, X. Multi-responsive and logic controlled release of DNA-gated mesoporous silica vehicles functionalized with intercalators for multiple delivery. Small 10, 980-988 (2014).

17. Dias, J. T. et al. DNA as a molecular local thermal probe for the analysis of magnetic hyperthermia. Angew. Chem. Int. Ed. 52, 11526-11529 (2013).

18. Lee, J. H. et al. Exchange-coupled magnetic nanoparticles for efficient heat induction. Nat. Nanotechnol. 6, 418-422 (2011).

19. Kappiyoor, R., Liangruksa, M., Ganguly, R. \& Puri, I. K. The effects of magnetic nanoparticle properties on magnetic fluid hyperthermia. J. Appl. Phys. 108, 094702 (2010).

20. Habib, A. H. et al. Evaluation of iron-cobalt/ferrite core-shell nanoparticles for cancer thermotherapy. J. Appl. Phys. 103, 07A307 (2008).

21. Rosensweig, R. E. Heating magnetic fluid with alternating magnetic field. J. Magn. Magn. Mater. 252, 370-374 (2002).

22. Mamiya, H. \& Jeyadevan, B. Hyperthermic effects of dissipative structures of magnetic nanoparticles in large alternating magnetic fields. Sci. Rep. 1, 157 (2011)

23. Breslauer, K. J., Franks, R., Blocker, H. \& Marky, L. A. Predicting DNA duplex stability from the base sequence. Proc. Natl. Acad. Sci. 83, 3746-3750 (1986).

\section{Acknowledgments}

Lina Yu was supported by China Scholar Council. The work was partially supported by the NSF MRSEC program facility, Institute on Environment fellow program and Institute of Engineering in Medicine seed grant at the University of Minnesota. The author Y.J. thanks the financial support from the National Basic Research Program of China (Grant No. 2015CB921502, 2012CB932702).

\section{Author contributions}

L.Y. conceived and designed the study, and carried out the numerical calculations. J.L. took all the TEM images, K.W. carried out the VSM test, and T.K. handled the magnetic fitting part. Prof. J.-P.W. and Prof. Y.J. planned and supervised the study. L.Y. wrote the paper and other authors gave out the amendments for manuscript. All authors contributed to the scientific discussions.

\section{Additional information}

Supplementary information accompanies this paper at http://www.nature.com/ scientificreports

Competing financial interests: The authors declare no competing financial interests.

How to cite this article: Yu, L. et al. Evaluation of Hyperthermia of Magnetic Nanoparticles by Dehydrating DNA. Sci. Rep. 4, 7216; DOI:10.1038/srep07216 (2014).

This work is licensed under a Creative Commons Attribution-NonCommercialShareAlike 4.0 International License. The images or other third party material in this article are included in the article's Creative Commons license, unless indicated otherwise in the credit line; if the material is not included under the Creative Commons license, users will need to obtain permission from the license holder in order to reproduce the material. To view a copy of this license, visit http:// creativecommons.org/licenses/by-nc-sa/4.0/ 